\title{
Maternal and Neonatal Outcomes among Obese Women with Gestational Weight Gain above the New Institute of Medicine (IOM) Recommendations
}

\author{
Elizabeth Restrepo, Fuqin Liu*
}

\begin{abstract}
Objectives: Gestational weight gain is important for optimal maternal and neonatal outcomes. New Institute of Medicine (IOM) recommendations for gestational weight gain define obesity as body mass index (BMI) $\geq 30$ and do not differentiate between maternal obesity classes. The recommended weight gain is $11-20 \mathrm{lbs}$. for obese women. The purpose of this study is to document prevalence of maternal obesity, excess gestational weight gain, and negative maternal and neonatal outcomes prior to 2009 IOM recommendations for gestational weight gain.

Materials and Methods: This was a retrospective cohort study using Texas birth/infant death certificate data for 2005 through 2009 , inclusive. The study population included 419,028 women. Those with excess ( $>20 \mathrm{lbs}$.) gestational weight gain were compared with those who gained the recommended 11-20 lbs.

Results: Compared to the recommended weight-gain group, women in the excessive weight-gain group had lower percentage of gestational diabetes, across three obesity classes. Women with excessive weight gain had higher percentage of pre-eclampsia and Cesarean delivery (C-section) than women in the recommended weight-gain group. Babies of women with excessive weight gain in Obesity Class III had higher percentages of Neonatal Intensive Care Unit (NICU) admission, assisted ventilation $>6$ hours, surfactant therapy, and antibiotics for suspected sepsis than babies of women in Obesity Class III, gaining within the IOM recommendation. Conclusion: Findings suggest that the relationships between maternal obesity classification, gestational weight gain, and maternal and neonatal outcomes are complex. Further evidence is needed to make recommendations on gestational weight gain for obese women, stratified by the severity of obesity.
\end{abstract}

Keywords: Gestational weight gain, 2009 IOM Guidelines, Pre-pregnancy obesity

\section{Introduction}

The prevalence of obesity is increasing worldwide, and the rates have more than doubled since 1980 (1). World Health Organization (WHO) defines overweight and obesity as "abnormal or excessive fat accumulation that may impair health" (1). Body Mass Index (BMI) is commonly used to classify overweight (BMI $25.0-29.9 \mathrm{~kg} / \mathrm{m}^{2}$ ), obesity $\left(\mathrm{BMI} \geq 30.0 \mathrm{~kg} / \mathrm{m}^{2}\right.$ ), and super obesity (BMI $\geq 40.0$ $\mathrm{kg} / \mathrm{m}^{2}$ ) (2). WHO further categorizes obesity into three classifications: Obesity Class I (BMI range from 30 to 34.99), Obesity Class II (BMI range from 35 to 39.99), and Obesity Class III (BMI $\geq 40)$ (3) but does not differentiate between Obesity Class I, Obesity Class II, and Obesity Class III in relation to weight-gain recommendations for pregnant women (4).

Obesity in reproductive-aged women has become a serious health issue (5). Further, a growing body of evidence demonstrates that pre-pregnancy obesity is associated with both adverse maternal and neonatal outcomes $(6,7)$.
Adverse maternal outcomes include gestational diabetes, preeclampsia, eclampsia, and Cesarean delivery (C-section) (8). Adverse neonatal outcomes can include macrosomia, respiratory distress, infection, and increased rates of Neonatal Intensive Care Unit (NICU) admission (9). To address concerns about the increasing prevalence of pre-pregnancy obesity and the associated maternal and neonatal risks, the Institute of Medicine (IOM) released new guidelines for gestational weight gain and provided a weekly weight-gain recommendation for the second and third trimesters (10). The new IOM guidelines, however, do not specify gestational weight-gain variations among different obesity classifications. Rather, the weight-gain recommendation for obese women is the same for all three WHO obesity classifications. The recommended range of total weight gain is 11-20 lbs., with a weekly weight gain of $0.5 \mathrm{lbs}$. in the second and third trimesters. Nevertheless, evidence suggests the impact of pre-pregnancy obesity on maternal and neonatal outcomes increases as the severity 
of obesity increases. It remains unclear whether recommendations for gestational weight gain should differ for each obesity classification. It is, therefore, important to examine the incidence of negative maternal and neonatal outcomes for each obesity class to supply evidence as to the total gestational weight gain needed, based on variations among obesity classifications.

Publication of the latest IOM guidelines for gestational weight gain marked an important development in prenatal care. To date, no published study has offered baseline data on the pattern of gestational weight gain prior to release of these guidelines. The purpose of this study, therefore, is to explore associations between excessive gestational weight gain and maternal and neonatal outcomes among obese women, stratified by severity of obesity. Additionally, we examine the patterns of gestational weight gain among obese women prior to the publication of the latest IOM guidelines. These baseline data will allow for future comparison of the effectiveness of the latest IOM guidelines for addressing gestational weight gain among the three classes of obese women. The research questions that guide this study are as follows:

1. What was the prevalence of maternal obesity as indicated on certificates of live births in Texas between 2005 and 2009?

2. Among women classified as obese, what was the pattern of gestational weight gain above the recommended range as indicated on certificates of live births in Texas between 2005 and 2009 ?

3. What was the prevalence of adverse maternal and neonatal outcomes for women in each obesity classification who exceeded the recommended gestational weight gain as indicated on certificates of live births in Texas between 2005 and 2009?

\section{Materials and Methods}

This was a retrospective, cohort study that used birth certificate data for the state of Texas for the years 2005 through 2009, inclusive; i.e., the data available to us at the time we undertook the study. A new U.S. birth certificate format was introduced in 2003; however, the state of Texas did not adopt the new format until 2005. For this reason, we chose to examine data from 2005 forward so that the data elements available were consistent across the five years.

Annual births in the state of Texas over the period 2005 through 2009 averaged approximately 400,000. This number represents roughly $10 \%$ of births that occur annually in the United States (11). Using SPSS, Version 19 (IBM SPSS Statistics), we examined maternal obesity in the state of Texas for five consecutive years, 2005 through 2009, inclusive. Our focus was on gestational weight gain and maternal and neonatal outcomes included in the birth certificate data set for women classified as obese.

We defined obesity using the latest IOM guidelines for maternal weight gain (10). The latest guidelines defined obesity as a BMI of 30 or greater. Because we needed to describe pre-pregnancy weight in terms of BMI, which is not available in the birth certificate data, we calculated pre-pregnancy BMI using data elements found in the birth certificate data, i.e., mothers' pre-pregnancy weight and height. We also calculated BMI at delivery using the birth certificate variable for weight at time of delivery and maternal height. Our BMI calculation was as follows: (mass in pounds)/(height in inches) $)^{2} \times 703$.

Based on mothers' calculated pre-pregnancy BMI, we created four weight groups:

(a) underweight, (b) normal weight, (c) overweight, and (d) obese. The obese population was comprised of 410,635 women, who represented approximately $21 \%$ of the total population of mothers who delivered over the five-year period. The obese women were divided into three classifications according to the WHO obesity definition: Obesity Classes I, II, and III. The study population included 239,075 women in Obesity Class I, 103,764 women in Obesity Class II, and 67,796 women in Obesity Class III, for a total of 410,635.

We calculated a maternal weight-gain variable by subtracting pre-pregnancy weight from weight at time of delivery. Gestational weight gain is important for optimal maternal and neonatal outcomes. The 2009 IOM recommendation for gestational weight gain varies according to pre-pregnancy weight categories (Table 1). As noted, for obese women, the IOM recommends a gestational weight gain of 11-20 lbs. Our focus was the obese women who exceeded this recommendation. For a comparison group, we used obese women who gained within the IOM recommendation.

We considered the following adverse pregnancy outcomes for the mother: gestational diabetes, preeclampsia, eclampsia, and C-section delivery. We considered the following adverse outcomes for the neonate: admission to the NICU, assisted ventilation for 6 hours or greater, antibiotics for the newborn with suspected sepsis, and surfactant therapy, information about all of which is found in the birth certificate data.

Cases that did not provide pre-pregnancy weight, weight at delivery or maternal height were removed from the data set because without these variables, pre-pregnancy BMI and BMI at delivery could not be calculated. A total of 8393 cases was removed from the full data set due to the lack of one or more of these variables, leaving an obese population comprised of 410,635 cases for the five years examined.

Frequencies were tabulated on the two gestational weightgain categories: within the recommended weight gain and above the recommended weight gain. To determine the trends of maternal and neonatal outcomes for each obesity class, we also calculated the frequencies of the four selected maternal outcome measures and of the four neonatal outcome measures. All analyses were conducted in SPSS, Version 19. 
Table 1. BMI categories and IOM gestational weight gain by category

\begin{tabular}{|c|c|c|c|c|}
\hline \multirow{2}{*}{$\begin{array}{l}\text { Gestational weight gain } \\
\text { categories }\end{array}$} & \multicolumn{3}{|c|}{ Number of cases and percentage in each obesity classification } & \multirow{2}{*}{$\begin{array}{c}\text { Total number of cases } \\
\text { No. inclusive of three } \\
\text { obesity groups }(410,635)\end{array}$} \\
\hline & Obesity Class I $(239,075)$ & Obesity Class II $(103,764)$ & Obesity Class III $(67,796)$ & \\
\hline$<11 \mathrm{lbs}(<4.99 \mathrm{~kg})$ & 11.4 & 16.0 & 20.4 & $58,617(14.1 \%)$ \\
\hline $11-20$ lbs (4.99-9.07 kg) & 23.8 & 25.6 & 25.4 & $102,021(24.5 \%)$ \\
\hline$>20 \mathrm{lbs}(>9.07 \mathrm{~kg})$ & 62.5 & 53.3 & 43.8 & $237,594(57.1 \%)$ \\
\hline
\end{tabular}

$\mathrm{BMI}=$ body mass index; $\mathrm{IOM}=$ Institute of Medicine; $\mathrm{lbs}=$ Weight in pounds; $\mathrm{kg}=$ Weight in kilograms

Note: Frequencies not summing to 100 reflect missing data; valid percentage reported.

\section{Results}

To obtain rates for the three obesity classes in regard to the IOM gestational weight-gain ranges, we calculated frequencies and percentages (Table 1). Of the obese women, $57.1 \%$ exceeded the recommended IOM gestational weight gain of 11-20 lbs. For all three obesity classes, the greatest percentage of women fell into the higher gestational weight-gain classification, that of greater than 20 lbs. For Obesity Class I, almost two-thirds (62.5\%) of the women gained more than the IOM recommendation.

Gestational weight-gain trends for all three obesity classifications indicated fluctuation over the five-year period (Table 2). For all three obesity classifications, the percentage of those who exceeded the recommended gestational weight gain was 2-2.5 times greater than the percentage of those who gained within the recommendation. For Obesity Class I, those who gained greater than the IOM recommendation of 11-20 lbs, represented $62.1-63 \%$ of the obese women in that classification over the five-year period of 2005-2009. For Obesity Class II, those who gained greater than the IOM recommendation represented 52.7-53.9\% of the obese women in that classification over the fiveyear period. For Obesity Class III, those who exceeded the IOM weight recommendation represented 43.5-44.2\% of the women in that classification for the five-year period. For Obesity Classes I and II, the greatest percentage of women who exceeded the recommended weight gain fell in the year 2007. For Obesity Class III, the greatest percentage of women who exceeded the recommended weight gain fell in the year 2006.

Evaluation of maternal outcomes for each obesity classification demonstrated that those who exceeded the recommended weight gain had higher percentages of pre-eclampsia and C-section delivery. Incidence of eclampsia in
Obesity Classes I and II was twice as high in the group who exceeded the recommended weight gain than the group who gained within the weight recommendation. For Obesity Class III, there was no difference. Interestingly, the findings for gestational diabetes for all three obesity classes revealed that those who exceeded the recommended weight gain had lower incidence of gestational diabetes as compared with those who gained within the weightgain recommendation (Table 3 ).

Examination of neonatal outcomes indicated that the incidence of macrosomia was higher in newborns of women who exceeded the recommended weight gain for all three obesity classes. In Obesity Classes I and II, the incidence of NICU admission, surfactant therapy, antibiotics for suspected sepsis, and assisted ventilation 6 hours or greater was the same or lower for newborns of women who exceeded the recommended weight gain as compared with those who gained within the recommendation. In Obesity Class III, for all the selected neonatal outcomes, incidence was higher among newborns of women who gained greater than the IOM recommendation (Table 4).

\section{Discussion}

Pre-pregnancy obesity is a serious public health issue. In our cohort of 410,635 women classified as obese, we examined women who gained above the IOM recommended gestational weight gain compared to those who gained within the recommendation. In our group of obese women, we found that approximately 3 out of 5 gained above the gestational weight gain recommended by the IOM, similar to the findings of Boyle et al. (12). This finding is also in keeping with that of Johnson et al., who found that approximately 3 out of 4 of the women in their group of nulliparous women, who may or may not have been obese,

Table 2. Gestational weight gain patterns by year for three obesity classes

\begin{tabular}{|c|c|c|c|c|c|c|c|c|c|c|}
\hline \multirow{3}{*}{ Obesity classes } & \multicolumn{10}{|c|}{ Year } \\
\hline & \multicolumn{2}{|c|}{2005} & \multicolumn{2}{|c|}{2006} & \multicolumn{2}{|c|}{2007} & \multicolumn{2}{|c|}{2008} & \multicolumn{2}{|c|}{2009} \\
\hline & $\begin{array}{l}\text { Within } 11-20 \\
\text { lbs.(4.99-9.07 } \\
\text { kg) (\%) }\end{array}$ & $\begin{array}{c}>20 \text { lbs. }(>9.07 \\
\text { kg) (\%) }\end{array}$ & $\begin{array}{l}\text { Within 11-20 } \\
\text { lbs.(4.99-9.07 } \\
\text { kg) (\%) }\end{array}$ & $\begin{array}{c}>20 \text { lbs. } \\
(>9.07 \mathrm{~kg}) \\
(\%)\end{array}$ & $\begin{array}{c}\text { Within } 11-20 \\
\text { lbs.(4.99-9.07 } \\
\text { kg) (\%) }\end{array}$ & $\begin{array}{c}>20 \text { lbs. } \\
(>9.07 \mathrm{~kg}) \\
(\%)\end{array}$ & $\begin{array}{c}\text { Within 11-20 } \\
\text { lbs.(4.99-9.07 } \\
\text { kg) (\%) }\end{array}$ & $\begin{array}{c}>20 \mathrm{lbs} . \\
(>9.07 \mathrm{~kg}) \\
(\%)\end{array}$ & $\begin{array}{l}\text { Within 11-20 } \\
\text { lbs.(4.99-9.07 } \\
\text { kg) (\%) }\end{array}$ & $\begin{array}{c}>20 \text { lbs. }(>9.07 \\
\text { kg) (\%) }\end{array}$ \\
\hline Obesity Class I & 24.1 & 62.1 & 24.2 & 62.2 & 23.5 & 63.0 & 23.6 & 62.6 & 23.6 & 62.6 \\
\hline Obesity Class II & 25.5 & 53.2 & 25.6 & 53.6 & 25.6 & 53.9 & 25.6 & 52.7 & 25.6 & 53.1 \\
\hline Obesity Class III & 25.5 & 43.6 & 25.6 & 44.2 & 25.0 & 43.8 & 25.5 & 43.5 & 25.3 & 43.8 \\
\hline
\end{tabular}

$\mathrm{lbs}=$ Weight in pounds; $\mathrm{kg}=$ Weight in kilograms

Note: Frequencies not summing to 100 reflect missing data; valid percentage reported 
Table 3. Selected maternal outcomes by obesity classifications

\begin{tabular}{|c|c|c|c|c|c|c|c|c|}
\hline \multirow{3}{*}{ Obesity classes } & \multicolumn{8}{|c|}{ Selected maternal outcomes } \\
\hline & \multicolumn{2}{|c|}{ Gestational Diabetes } & \multicolumn{2}{|c|}{ Pre-eclampsia } & \multicolumn{2}{|c|}{ Eclampsia } & \multicolumn{2}{|c|}{ C-section Delivery } \\
\hline & $\begin{array}{c}\text { Incidence among } \\
11-20 \mathrm{lbs} .(4.99- \\
9.07 \mathrm{~kg})(\%)\end{array}$ & $\begin{array}{c}\text { Incidence among } \\
>20 \mathrm{lbs} .(>9.07 \\
\mathrm{kg})(\%)\end{array}$ & $\begin{array}{c}\text { Incidence among } \\
11-20 \mathrm{lbs} .(4.99- \\
9.07 \mathrm{~kg})(\%)\end{array}$ & $\begin{array}{c}\text { Incidence among } \\
>20 \mathrm{lbs} .(>9.07 \\
\text { kg) (\%) }\end{array}$ & $\begin{array}{l}\text { Incidence among } \\
11-20 \mathrm{lbs} .(4.99- \\
9.07 \mathrm{~kg})(\%)\end{array}$ & $\begin{array}{c}\text { Incidence among } \\
>20 \mathrm{lbs} .(>9.07 \\
\text { kg) (\%) }\end{array}$ & $\begin{array}{c}\text { Incidence among } \\
11-20 \mathrm{lbs} .(4.99- \\
9.07 \mathrm{~kg})(\%) \\
\end{array}$ & $\begin{array}{c}\text { Incidence among } \\
>20 \mathrm{lbs} .(>9.07 \\
\mathrm{kg})(\%)\end{array}$ \\
\hline Obesity Class I & 6.7 & 5.4 & 5.2 & 7.4 & 0.1 & 0.2 & 38.5 & 44.7 \\
\hline Obesity Class II & 8.3 & 6.9 & 7.2 & 9.7 & 0.1 & 0.2 & 46.1 & 51.9 \\
\hline Obesity Class III & 9.4 & 8.7 & 9.7 & 12.1 & 0.2 & 0.2 & 54.7 & 61.0 \\
\hline
\end{tabular}

$\mathrm{lbs}=$ Weight in pounds; $\mathrm{kg}=$ Weight in kilograms

Note: Frequencies not summing to 100 reflect missing data; valid percentage reported.

Table 4. Selected neonatal outcomes by obesity classifications

\begin{tabular}{|c|c|c|c|c|c|c|c|c|c|c|}
\hline \multirow[b]{3}{*}{ Obesity Classes } & \multicolumn{10}{|c|}{ Selected neonatal outcomes } \\
\hline & \multicolumn{2}{|c|}{ NICU Admission } & \multicolumn{2}{|c|}{ Surfactant Therapy } & \multicolumn{2}{|c|}{$\begin{array}{c}\text { Antibiotics for Newborn with } \\
\text { Suspected Sepsis }\end{array}$} & \multicolumn{2}{|c|}{$\begin{array}{c}\text { Assisted Ventilation } 6 \text { Hours } \\
\text { or Greater }\end{array}$} & \multicolumn{2}{|c|}{ Macrosomia } \\
\hline & $\begin{array}{l}\text { Incidence } \\
\text { among 11-20 } \\
\text { lbs. (4.99-9.07 } \\
\text { kg) (\%) }\end{array}$ & $\begin{array}{l}\text { Incidence } \\
\text { among >20 } \\
\text { lbs. }(>9.07 \\
\text { kg) (\%) }\end{array}$ & $\begin{array}{l}\text { Incidence } \\
\text { among 11-20 } \\
\text { lbs. (4.99-9.07 } \\
\text { kg) (\%) } \\
\end{array}$ & $\begin{array}{l}\text { Incidence } \\
\text { among >20 } \\
\text { lbs. (>9.07 } \\
\text { kg) (\%) }\end{array}$ & $\begin{array}{l}\text { Incidence among } \\
11-20 \mathrm{lbs} .(4.99- \\
9.07 \mathrm{~kg} \text { ) (\%) }\end{array}$ & $\begin{array}{l}\text { Incidence } \\
\text { among >20 } \\
\text { lbs. }(>9.07 \\
\text { kg) (\%) }\end{array}$ & $\begin{array}{l}\text { Incidence } \\
\text { among 11-20 } \\
\text { lbs. (4.99-9.07 } \\
\text { kg) (\%) }\end{array}$ & $\begin{array}{l}\text { Incidence } \\
\text { among >20 } \\
\text { lbs. }(>9.07 \\
\mathrm{kg})(\%)\end{array}$ & $\begin{array}{l}\text { Incidence } \\
\text { among 11-20 } \\
\text { lbs. (4.99-9.07 } \\
\text { kg) (\%) }\end{array}$ & $\begin{array}{l}\text { Incidence } \\
\text { among }>20 \\
\text { lbs. }(>9.07 \\
\text { kg) (\%) }\end{array}$ \\
\hline Obesity Class I & 7.2 & 6.8 & 0.4 & 0.3 & 1.7 & 1.7 & 1.3 & 1.2 & 6.2 & 10.2 \\
\hline Obesity Class II & 8.0 & 7.8 & 0.4 & 0.3 & 1.9 & 1.8 & 1.5 & 1.3 & 8.1 & 12.1 \\
\hline Obesity Class III & 9.2 & 9.6 & 0.4 & 0.5 & 2.0 & 2.1 & 1.6 & 1.8 & 10.2 & 13.9 \\
\hline
\end{tabular}

$\mathrm{NICU}=$ Neonatal intensive care unit; lbs= Weight in pounds; $\mathrm{kg}=$ Weight in kilograms

Note: Frequencies not summing to 100 reflect missing data; valid percentage reported.

gained above the IOM recommendation (13). Iyoke et al. reported similar findings, specifically, that obese women are less likely to have excessive weight gain during early pregnancy as compared to healthy-weight women (14). Further, we found that women in Obesity Class I had the highest percentage of weight gain above the recommendation, indicating that women who are less obese are more likely to exceed the recommended weight gain. This is in line with the findings reported by Bodnar et al. (15). One possible explanation for this finding is that severely obese women are more likely than less obese women to closely watch their weight gain during pregnancy. More studies are needed to further validate this supposition; however, our finding serves as caution to practitioners to monitor less obese women's gestational weight gain more closely. Of the maternal outcomes that we examined, including gestational diabetes, pre-eclampsia, eclampsia, and C-section delivery, we found that the incidence of these outcomes was higher in Obesity Class III in both women who gained within and those who gained above IOM recommendations. Blomberg found that women in Obesity Classes II and III who lost weight during pregnancy had a decreased risk for C-section delivery and an unaffected risk for preeclampsia (16). Although we examined women who gained weight during pregnancy, we found that there was a higher incidence of adverse maternal outcome in Obesity Classes II and III for those who gained above the IOM recommendation. We found that the incidence of C-section delivery increased as the severity of obesity increased and that the incidence was higher among women who gained above the IOM recommendation as compared to those who gained within the rec- ommendation. In contrast to the Blomberg study (16), we found that the incidence of pre-eclampsia increased as the severity of the obesity increased. Oza-Frank and Keim found that women with excessive gestational weight gain were more likely to have preeclampsia than were women with inadequate weight gain (17). However, the incidence of gestational diabetes among obese women who exceeded the IOM recommendation was lower than those who gained within the IOM recommendation. This was true for all three obesity classifications. Beyerlein et al. reported similar findings with regard to gestational diabetes in obese women who gained weight (18).

Comparable to the findings of Langford et al. (19), we found that the incidence of pre-eclampsia, C-section delivery, and macrosomia increased as gestational weight gain increased, across all three obesity classifications. To add to the evidence on the connection between gestational weight gain and pregnancy outcomes, our study examined several neonatal outcomes: NICU admission, surfactant therapy, antibiotics for newborn with suspected sepsis, and assisted ventilation 6 hours or greater, which have not been reported in the literature $(13,15,16,19)$.

In conclusion, gestational weight gain above the IOM recommendation is linked to higher incidence of pre-eclampsia, eclampsia, C-section delivery, and macrosomia. Further, incidence of all neonatal outcomes examined was higher in the group with weight gain above the IOM recommendation. Our study indicated that women in Obesity Class III were less likely to exceed the IOM recommendation on gestational weight gain but were more likely to have adverse outcomes. This finding confirms evidence from extant literature that the impact of pre-pregnancy 
obesity on maternal and neonatal outcomes increases as the severity of obesity increases.

This study has several limitations. Firstly, the data were derived from the state of Texas birth certificates. Researchers did not abstract data manually from the prenatal or post-partum records and were limited to using the data elements available in the birth certificate data set. Secondly, the study did not include the neonatal outcomes of small for gestational age and large for gestational age neonates, outcomes often measured when examining gestational weight gain (20). Thirdly, the researchers used only descriptive statistics to characterize the study population; thus, no causal inferences could be made in regard to the relationship between gestational weight gain and maternal and neonatal outcomes.

Another limitation was that there were cases within the birth certificate data file that were missing one or both of the variables needed to calculate pre-pregnancy weight and BMI. We, therefore, removed those cases from the analysis. A total number of 8393 cases with missing data was removed, approximately two percent of the total cases meeting the criteria to be included in the study sample.

\section{Ethical issues}

The study was approved by Texas Woman's University Institutional Review Board.

\section{Financial support}

This study was supported by Texas Woman's University College of Nursing Dean's Development Fund.

\section{Conflict of interests}

The authors have no conflicts of interest to disclose.

\section{Acknowledgments}

We would like to thank Dr. Patti Hamilton at Texas Woman's University for providing comments on the research questions guiding the study.

\section{References}

1. World Health Organization. Obesity and overweight. Accessed 2014 July. Available from: http://www.who. int/mediacentre/factsheets/fs311/en/

2. National Center for Health Statistics. Prevalence of overweight obesity, and extreme obesity among adults: United States, trends 1960-1962 through 2009-2010. Accessed 2014 July. Available from: http:// www.cdc.gov/nchs/data/hestat/obesity_adult_09_10/ obesity_adult_09_10.pdf

3. World Health Organization. BMI classification. Accessed 2014 July. Available from: http://apps.who. int/bmi/index.jsp?introPage=intro_3.html

4. American College of Obstetricians and Gynecologists. ACOG Committee opinion no. 549: obesity in pregnancy. Obstet Gynecol 2013; 121(1): 213-7.
5. Leddy MA, Power ML, Schulkin J. The impact of maternal obesity on maternal and fetal health. Rev Obstet Gynecol 2008; 1(4): 170-8.

6. Birdsall KM, Vyas S, Khazaezadeh N, Oteng-Ntim E. Maternal obesity: a review of interventions. Int J Clin Pract 2009; 63(3): 494-507. doi: 10.1111/j.17421241.2008.01910.x.

7. Hoff GL, Cai J, Okah FA, Dew PC. Pre-pregnancy overweight status between successive pregnancies and pregnancy outcomes. J Womens Health (Larchmt) 2009; 18(9): 1413-7. doi: 10.1089/jwh.2008.1290.

8. Zhang Y, Wang ZL, Liu B, Cai J. Pregnancy outcome of overweight and obese Chinese women with gestational diabetes. J Obstet Gynaecol 2014; 34(8): 662-5. doi: 10.3109/01443615.2014.920787.

9. Yu Z, Han S, Zhu J, Sun X, Ji C, Guo X. Pre-pregnancy body mass index in relation to infant birth weight and offspring overweight/obesity: a systematic review and meta-analysis. PLoS One 2013; 8(4): e61627. doi: 10.1371/journal.pone.0061627.

10. Institute of Medicine. Weight gain during pregnancy: reexamining the guidelines. Washington, DC: The National Academies Press; 2009.

11. Martin JA, Hamilton BE, Ventura SJ, Osterman MJ, Wilson EC, Mathews TJ. Births: final data for 2010. Natl Vital Stat Rep 2012; 61(1): 1-72.

12. Boyle A, Timofeev J, Halscott T, Desale S, Driggers RW, Ramsey PS. Is 40 the new 30? Pregnancy outcomes by degree of weight gain among obesity subclasses. Obstet Gynecol 2014; 123(Suppl 1): 41S. doi: 10.1097/01.AOG.0000447320.82646.64.

13. Johnson J, Clifton RG, Roberts JM, Myatt L, Hauth JC, Spong CY, et al. Pregnancy outcomes with weight gain above or below the 2009 Institute of Medicine guidelines. Obstet Gynecol 2013; 121(5): 969-75. doi: 10.1097/AOG.0b013e31828aea03.

14. Iyoke CA, Ugwu GO, Ezugwu FO, Lawani OL, Onyebuchi AK. Retrospective cohort study of the effects of obesity in early pregnancy on maternal weight gain and obstetric outcomes in an obstetric population in Africa. Int J Womens Health 2013; 5: 501-7. doi: 10.2147/IJWH.S49909.

15. Bodnar LM, Siega-Riz AM, Simhan HN, Himes KP, Abrams B. Severe obesity, gestational weight gain, and adverse birth outcomes. Am J Clin Nutr 2010; 91(6): 1642-8. doi: 10.3945/ajcn.2009.29008.

16. Blomberg M. Maternal and neonatal outcomes among obese women with weight gain below the new Institute of Medicine recommendations. Obstet Gynecol 2011; 117(5): 1065-70. doi: 10.1097/ AOG.0b013e318214f1d.

17. Oza-Frank R, Keim SA. Should obese women gain less weight in pregnancy than recommended? Birth 2013; 40(2): 107-14. doi: 10.1111/birt.12037.

18. Beyerlein A, Lack N, von Kries R. Within-population 
average ranges compared with Institute of Medicine recommendations for gestation weight gain. Obstet Gynecol 2010; 116(5): 1111-8. doi: 10.1097/ AOG.0b013e3181f1ad8b.

19. Langford A, Joshu C, Chang JJ, Myles T, Leet T. Does gestational weight gain affect the risk of adverse maternal and infant outcomes in overweight women?
Matern Child Health J 2011; 15(7): 860-5. doi: 10.1007/s10995-008-0318-4.

20. Simas TA, Waring ME, Liao X, Garrison A, Sullivan GM, Howard AE, et al. Prepregnancy weight, gestational weight gain, and risk of growth affected neonates. J Womens Health 2012; 21(4): 410-7. doi: $10.1089 /$ jwh.2011.2810

Copyright $\odot 2015$ The Author(s); This is an open-access article distributed under the terms of the Creative Commons Attribution License (http://creativecommons.org/licenses/by/4.0), which permits unrestricted use, distribution, and reproduction in any medium, provided the original work is properly cited. 